\title{
ONE THE PECULIARITIES OF MODERN MUSICAL FOLKLORE OF SHIRAK
}

\author{
Hasmik Harutyunyan, PhD in Art Studies, Yerevan State Conservatory after Komitas Gyumri Branch \\ (Director), Shirak Centre for Armenological Studies NAS RA \\ Hasmik Matikyan, PhD in Philology, Yerevan State Conservatory after Komitas Gyumri Branch \\ (Lecturer), Shirak Centre for Armenological Studies NAS RA \\ DOI: https://doi.org/10.31435/rsglobal_conf/25122020/7307
}

\begin{abstract}
In different rural communities of Shirak region nowadays live representatives of the Armenain generation who have immigrated from Western Armenia and bear unique musical specimen. They are folk and national multi-genre song types and musical instrumental works. In the article we have touched upon 100 folk songs compiled from the folkloristic material organized in about 20 communities of Shirak region in 2015 March-April, that not only give us common notion of the song tradition of our compatriots migrated from Moush and Alashkert, in 2015, but they also certify that the tradition of folk song creativity is alive and coexists next to the very different modern cultural manifestations.
\end{abstract}

Keywords: Ethnomusicology, Musical folklore, Shirak regon, traditional music, folk song, study, revival.

The musical heritage of Shirak of the $19^{\text {th }}-20^{\text {th }}$ centuries has its unique place and role in the development of the Armenian national music. The rich musical folklore, imbued with the genrestylistic features of the musical dialects of Western Armenia, became the basis for the unprecedented development of the professional music of the oral tradition and the creation of a valuable heritage. From the second half of the $19^{\text {th }}$ century Armenian philologists and musician-folklorists became interested in the flourishing art of the Armenian bards and folk music players of Shirak. Komitas, Alexander Mkhitaryan, Arshak Brutyan, Nikoghayos Tigranyan, Spiridon Melikyan, Aram Kocharyan, Robert Atayan, Margarit Brutyan not only collected and coordinated, but also valued this heritage with high standards. The absolute dominance of the diverse Armenian national image, on the one hand, and the unique cultural manifestations of national minorities and their relations, on the other hand, gradually formed a new unique Armenian urban cultural life, which was characterized by its stable and original traditions in the late $19^{\text {th }}$ century. Gradually, a multi-genre system of song-music in urban life was established, acquiring local musical-style features at the beginning of the $20^{\text {th }}$ century.

As musician-folklorist H. Apinyan rightly noticed: "The study of the musical folklore of ethnographic regions is a problem in Armenian folklore. Valuable collections, separate studies and articles published on the basis of the work in this sphere today expand the boundaries of musicology, requiring new methodological approaches to problem solving, modern ways of comparative analysis, which will lead to new assessments of the musical artistic phenomenon. The musical folklore of Shirak is one of the richest repositories of Armenian folk music, where many traditional songs, instrumental tunes and musical-poetic compositions preserved with amazing purity have a deep stamp of antiquity. Many of them still maintain their viability and result in folk artistic thinking. Indeed, the roots of many orally transmitted musical values are in the depths of historical Armenia, in the provinces of Moush, Alashkert, Erzrum, and in other places with many songs. However, the people displaced from their homeland due to the well-known historical events, and relocated to Shirak, in contact with the locals, enrich their verbal and musical language with the nuances of the place in time, which leads to new layers of musical thinking". (1)

It should be noted that this refers to both folk songs and instrumental and dance music. It is known that in the $19^{\text {th }}$ century, as a result of well-known geopolitical, historical and cultural processes, Alexandrapol became the direct bearer of the urban cultural values of Western Armenia (Kars, Karin, Moush). Folk dance had a unique expression in the cultural realities, especially in the musical life of the city, which was experiencing craftsmanship, trade and economic development. Like other genres of folk music, traditional dance carried new functional and aesthetic qualities, which were conditioned by the predominance of the Armenian ethnic cultural element (95\% of the city's population were Armenians) on the one hand, and by active contacts with neighboring peoples on the other hand, which made the mastery of the so-called Caucasian dances contemporary. As in other Armenian cities of the $19^{\text {th }}$ century, the dances existing in Alexandropol are included in three groups according to their functions: ritual, household or feast, competitive. ${ }^{2}$ The main features of the Alexandropol traditional dance, under the 
direct influence of the Western Armenian urban dance culture, stimulated the development of local unique patterns. Thus, at the end of the 19th century, Kochari, Klor dance, Erzrum Armenian dance, Mshu dance, Tamzara dances, which were very popular, were accompanied by Kalos prken, Gyumri trngi, Ghashange, Totik-totik dances and dance songs having a unique local coloring and expressiveness. They played a great role in preserving the traditional dance, especially the national identity of the dance music, which underwent various transformations in the musical life of Leninakan in the $20^{\text {th }}$ century. If the moving text of urban folk dance (especially odd /odd/) and even) was characterized by the freedom and ease of dance steps, then the melodic component, along with the variety of dances of the same name, is characterized as a unique, unchanging unit. Due to the bright talent of the outstanding music performers in the musical life of Leninakan, the traditional dances were performed not only in everyday life and in city gatherings, but also on stages and on TV and radio. It is not accidental that the great Armenian composer Aram Khachatryan used the dance "Kalos prken" as the sound symbol-bells of Leninakan. Assessing the place and role of the Alexandropol-Leninakan traditional dance within the mentioned period, it is necessary to use the unique significance of that heritage, as a value bearing typical features of ethnic identity, in the formation and development of the Armenian national composing art. Let us mention the basic principles of quoting and composing them in the works of Komitas, N. Tigranyan, A. Tigranyan, A. Spendiaryan, A. Ter-Ghevondyan, which are again based on the inner possibilities of the original musical expressions of those dances.

According to Komitas, "The gift of composing a song is a natural gift for a peasant", everyone, good or bad, knows how to play and sing. ... For the builder, his daily creation has no value, it is an involuntary demand like bread and water. The villager despises many types of his songs, laughs at those who are educated, that they write carefully, collect those "naughty things and girl games". The main goals of folk art are beyond the artistic spheres, although primarily realized through artistic means, which is beyond doubt. Combining the many private titles of folk music, folklorists have concluded that its ultimate function is "the reproduction of humanity in a person". Not abstract humanity in general, but a rather specific one, historically predetermined by a given cultural tradition, to which every emerging individual must communicate in one way or another". (2)

Thus, it can be argued that folk song, like folk art in general, lives and functions almost according to the laws of organic nature. Therefore, as a "living organism", folk song coexists with some elements of external phenomena, preserving the backbone or basis of the composition of the work due to their assimilation.

Time is a very complex and influential factor in any manifestation of traditional, intangible culture, especially in the survival and preservation of folk songs. In the context of changing the living environment of folk song and some issues threatening the cultural ecology, we have tried to consider the special manifestations of song folklore "living" in a number of rural communities of Shirak.

At the beginning of the $21^{\text {st }}$ century, despite the influence of modern globalization processes (television, internet, other means of communication), folk songs were played in any village in the Shirak region, with a predominance of local samples. The bearers and performers of the material are mainly elderly people, who treat the musical relics inherited from the older generation like sacred relics. Thus, a large group of songs that interest us should be seen as a legacy passed down from previous generations. Consequently, most of these songs live and survive as a memory. This is the reason for the transformed image of the song genre system: selective, preferred genres have been preserved. Here it is appropriate to quote the observations made by musicologist A. Pahlevanyan on the issue: "Due to the compulsion of time, some genres are pushed out of the musical life of the people. The folklore genre misses time compared to several reasons. a) loses its creative soil, the obligatory conditions in which it is born, develops, is transferred, that is, is cut off from its historical-geographical, social-psychological bases /epic poetry, historical songs, songs of exile/", b) loses its function /spiritual, ritual, work songs/, c) with the change of social-psychological factors, it leaves the system of human perception of art, as a genre it ceases to be a demanding requirement (lullabies, children's games, daily-work-life songs), d) the complex musical-poetic structure requires a high level of performance, almost professional-traditional transfer and excludes accidental bearing and performance, easy transfer of the contribution (prosody, epic poetical, work, ritual, troubadour)". (2) The dance genre occupies a unique place with its genre vitality. The importance of the musical, dance and poetic art of folk rural dances has been great in the Armenian centuries-old culture as the most intimate, most reliable and vital starting point of the folk art.

In different communities of Shirak it is still found today under the names of khagh, khana, taghalo, mani. 
There are songs with repetitions, as well as without repetitions with simple melodic compositions. Some of them are separated from different rituals and live independently. The symmetrical to asymmetrical ratios of stressed syllables have a strong expression. The viability of the genre is due first to the presence of repetitive components, and then to the diversity of content. This is the reason why songs of different ritual and everyday situations are intertwined in the genre of dance songs. Unique samples of hard dance songs, have been preserved next to the small songs. The ritual songs are various. They are dominated by wedding and Ascension songs. Their newness is conditioned by their variety and vitality, especially in the wedding ceremony. The range of epic songs is limited to the songs of troubadour romances, as well as the songs of individual troubadours. These samples need special analysis, as the melodies of many of them live a standardized, independent life, adapting to the poem of a new individual author. Literary Armenian predominates in the poetic texts of the songs, which testifies to the transformations of their original versions. We believe that this phenomenon is not only a result of the time and new environment, but also of being influenced by troubadour songs.

The problems of the vital ontology of the works of the oral tradition and the methodological peculiarities of their study occupy a special place in various ethnomusicological researches. In folklore, the classical heritage is not a selection of songs, but a unique genetic fund of musical expression, which is instinctively protected in the conditions of activity of ethnic interests and interactions. $12 \mathrm{~A}$ recorded folk song can last a long time. However, the tradition of the creative mechanism of songwriting based on centuries of genetic memory and experience, can only exist if the conditions for the creation and performance of new songs exist. In the modern folklore of Shirak, there are few examples of songs created by the living tradition of songwriting. They are, of course, the product of the talent of individual composers. It is important that these songs, created in a community micro-environment, are performed as traditional classical samples.

In this respect, the lullabies and tragic songs occupy a special place, the genre peculiarities of which allow the performer of the song to freely create, to compose the musical-poetic composition with ease, according to the feelings and emotional state of the moment. Many of the song performers refer to the samples heard from their elders, but even a simple analysis reveals their sudden individual nature, which is the best evidence of the vitality and original manifestations of the songwriting tradition.

Dans song "Asmara man-aman"

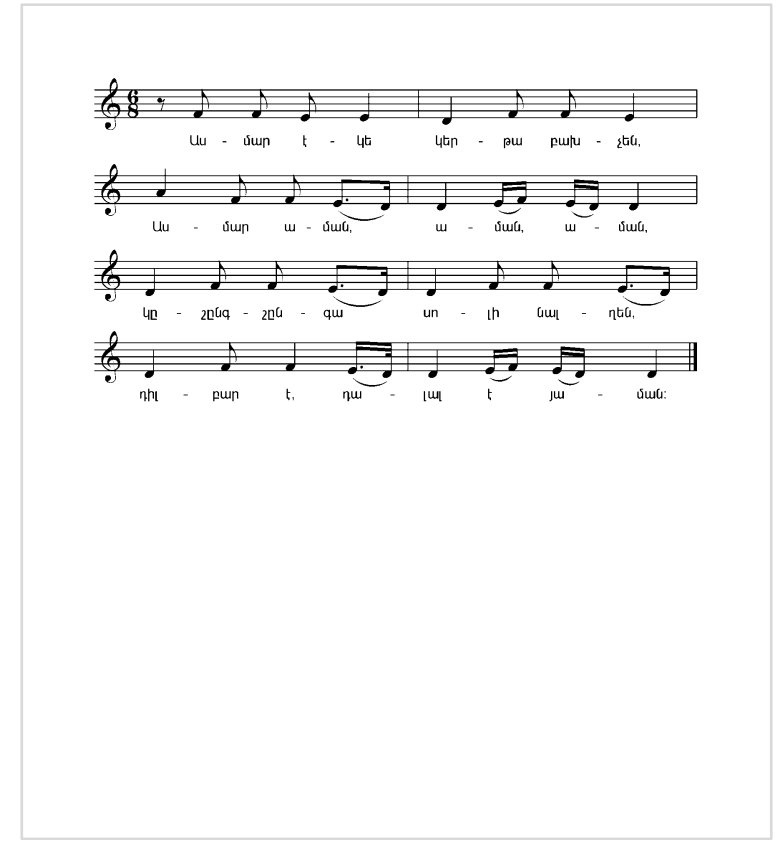

\section{REFERENCES}

1. Apinyan H., Observations on the study of Shirak folk music. Materials of the Seventh Republican Scientific Session "Historical and Cultural Heritage of Shirak", Gyumri, 2007, p. 234.

2. Khachatryan Zh., Dance in Armenian, Yerevan, 2013, pages 10-11. n Zh., Dance in Armenian, Yerevan, 2013, pages 10-11. 